\title{
Correction: FGFR1-ERK1/2-SOX2 axis promotes cell proliferation, epithelial-mesenchymal transition, and metastasis in FGFR1-amplified lung cancer
}

\author{
Kaixuan Wang $\cdot$ Wenxiang Ji $\cdot$ Yongfeng Yu $\cdot$ Ziming Li $\cdot$ Xiaomin Niu $\cdot$ Weiliang Xia $(D)$ Shun Lu
}

Published online: 7 September 2020

(c) Springer Nature Limited 2020

Correction to: Oncogene

https://doi.org/10.1038/s41388-018-0311-3
After publication of this article, the authors noted that an incorrect image of $\mathrm{N}$-cadherin was included in Fig. $5 \mathrm{f}$ for the DMS114 LV-SOX2 vehicle group.

The figure has been corrected in the HTML and PDF versions of the article. 
Fig. 5

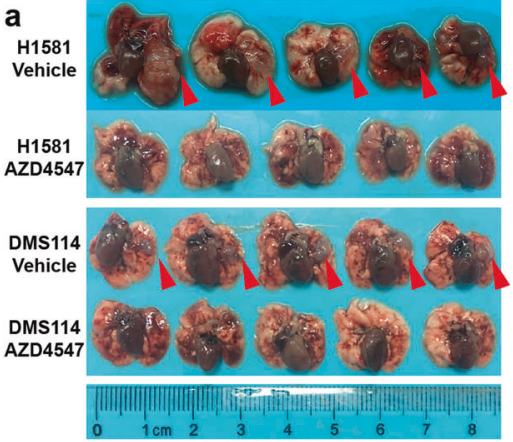

H158

Vehicle

H1581

LV-SOX2

Vehicle

LV-SOX2

AZD4547

DMS114

VV-NC

DMS114

LV-SOX2

Vehicle

AZD4547

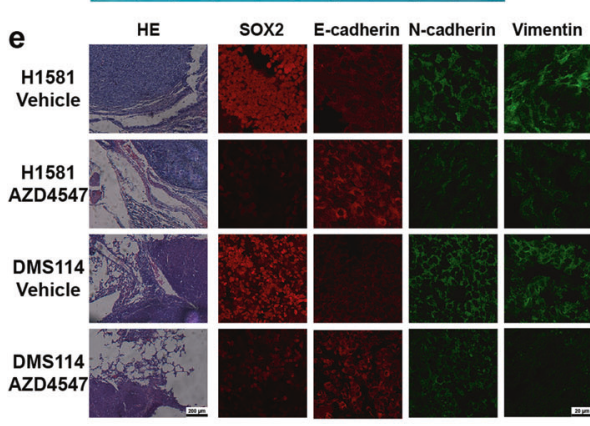

g

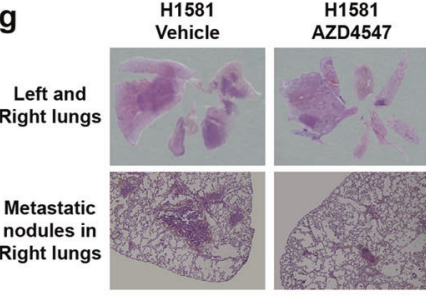

h
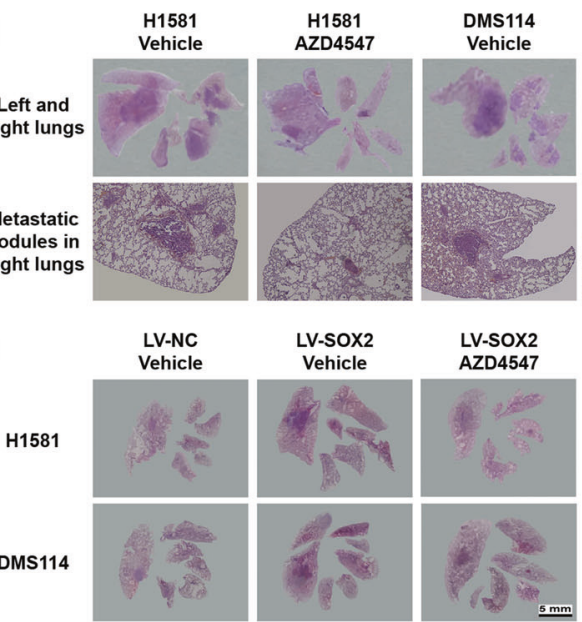

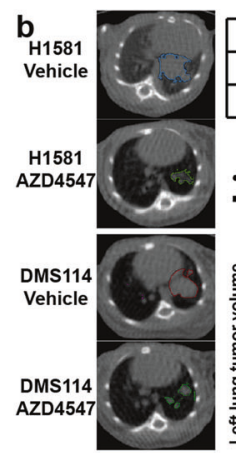

${ }^{15} \mathrm{~mm}$

$-10 \mathrm{~mm}$

$L_{0}^{-5}$

- Vehicle

- AZD4547

$12.5 \mathrm{mg} / \mathrm{kg} / \mathrm{d}$

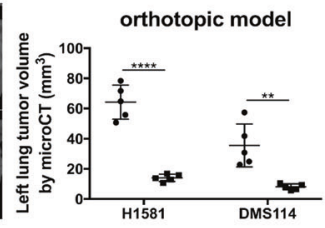

d LV-NC Vehicle

- LV-Soxz Vehicle

- LV-SOX2 Vehicle

$12.5 \mathrm{mg} / \mathrm{kg} / \mathrm{c}$

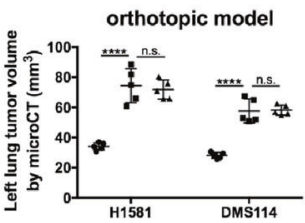

f

H1581 LV-NC

Vehicle

H1581
LV-SOX2 LV-sox2
Vehicle

LV-SOX

AV-SOX2

DMS114

LV-NC

Vehicle

DMS114

LV-SOX2

Vehicle

DMS114

LV-SOX2

AZD 4547

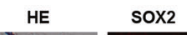

SoX2 E-cadherin $\mathrm{N}$-cadherin Vimentin

DMS114 • vehicle

AZD4547 - AZD4547
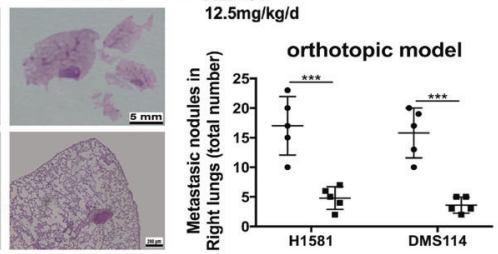

- LV-NC Vehicle

- LV-Sox2 Vehicle

LV-SOX2 AZD4547

H1581
DMS114 